\title{
Depreciation Test of Fixed Assets - Necessity, Indices of Value Loss, Certainty and Frequency of Assessment Evaluation
}

\author{
Marinela-Daniela Manea, Valahia University Targoviste, Romania \\ Elena Violeta Drăgoi, Valahia University Targoviste, Romania
}

\begin{abstract}
With the promulgation of IAS 36 "Depreciation of Assets" to ensure a consistent approach of reversible loss of value, removing the specific nationals practices and such the differences what appear as a result of the different treatments. In the chain of procedures for determining the depreciation of an asset/cash generating unit is required first the crossing phase of identification to an possible impaired assets, being necessary for the strict professional reasoning to each business. Applying the test impairment is not random and not to all assets of an enterprise. In general, the standard requires for companies to make the impairment tests when there are signs that an asset may be impaired (but annually for intangible assets with an indefinite useful life and commercial fund). The opportunity given by IAS 36 " Depreciation of Assets" to choose in determining of recoverable amount, between two values is not accidental. It is considered that the company can recover the value of its assets through use or market capitalization. However measurement of the two values is a complex process, very expensive for many businesses, own estimates based on Management Company with a strong subjective load, which is reflected on the certainty and reliability of obtained data.
\end{abstract}

\section{Keywords}

Professional judgment; Amount of use; Net fair value.

JEL Code: M41, G31

\section{Depreciation of the Romanian Accounting Sense Before Harmonization With International Accounting Standards}

Romanian accounting -before harmonization with International Accounting Standards, deemed necessary to four times the valuation of property elements namely: the entry into property, the inventory, the closure and out of the assets. Impairment of value was addressed through the accounting structures of the nature of provisions and payments. For measurement of the reversible impairment of value, according to Romanian accounting standards, attention is stopped on the inventory evaluation. Valuation of assets ${ }^{1}$, at inventory, emphasized, especially in practice, on the quantitative than qualitative side. During the inventory, evaluation of intangibles assets is made on the actual value or utility of each element, called

\footnotetext{
${ }^{1}$ M. Ristea, "Guide for the understanding and application of International Accounting Standards - IAS 36", Publishing House CECCAR, Bucharest, 2004
} 
inventory value determined by the usefulness of the asset in business, by his physical condition and market price. For properties (tangible and intangible) held in inventory depreciation values to take account of depreciation deduction calculated for the purposes of its asset value was given by the net book value of depreciation resulting from the amortization plan unless the actual value was considered to be lower than net accounting value.

In closing of the exercise the input value of property is compared with the utility value (present value) determined during the inventory.

Following this comparison, are resulting two situations:

- finding some valuable pluses between asset value and input value, which in application of the principle of prudence, there were no record in the accounts;

- the discovery of weaknesses of value between asset value and input value of property is recorded in the accounts as an exceptional depreciation when depreciation was irreversible or was a provision when impairment was reversible, caused by factors such as:

a. the emergence of a moral wear that was not taken into account at depreciation;

b. overstatement of fixed assets by applying inappropriate factors when assessing their

c. Their lack of utility for the enterprise, when the inventory (in storage, not used for activities at the time of inventory, etc...)

d. Other reasons which determine a current value lower than the value that they were included in the accounts. Depreciation was regarded as the equivalent value of irreversible impairment of fixed assets because of the use, of natural factors, technical progress or other causes for impairment with reversible character and temporary to be treated by the provisioning.

\section{International Standards for Financial Reporting is Treating Different Depreciation Issues.}

Was induced term of depreciated value (deprived value) with another meaning than the frequently used in romanian practice. Is prescribed as necessary to reflect an asset in the financial statements at an amount who don't must exceed the recoverable amount obtained from the use or trading on an active market. The concept was developed precisely to provide a better and reliable reflection of the value of an asset on the balance sheet in the financial statements of an enterprise. And this because, in practice, in many European jurisdictions, although there were statutory obligations of comparing the book value of assets with market value of their requirements were not necessarily applied rigorously. Furthermore, some jurisdictions, particularly those with legal tradition-British trade, imposed not reflect depreciation, unless it is made into a permanent and long term. More rigorous approach of IAS 36 reflects the fact that authorities have become aware that this was a neglected area in financial reporting. Thus, on balance, in accordance with IAS 36 is comparing the accounting value of fixed assets to his fair value and present value of estimated cash flows to be generated through use - the amount of use. If most of these values are less than the carrying amount, impairment is recognized. The purpose of the above mentioned rule is precisely to prescribe all procedures that apply to an undertaking to ensure that its assets are recorded at a value greater than their recoverable amount. To understand the establishment of the recoverable value from fixed assets we follow the diagram below: 
Regarding the future economic benefits attached to an asset is expected:

a) Significant changes occur in the manner or the use of the asset, or

b) Economic performance of the asset to be lower than initial expectations, or

c) The market value of the asset has declined significantly over initial projections, or

d) Asset is spent physically or morally.

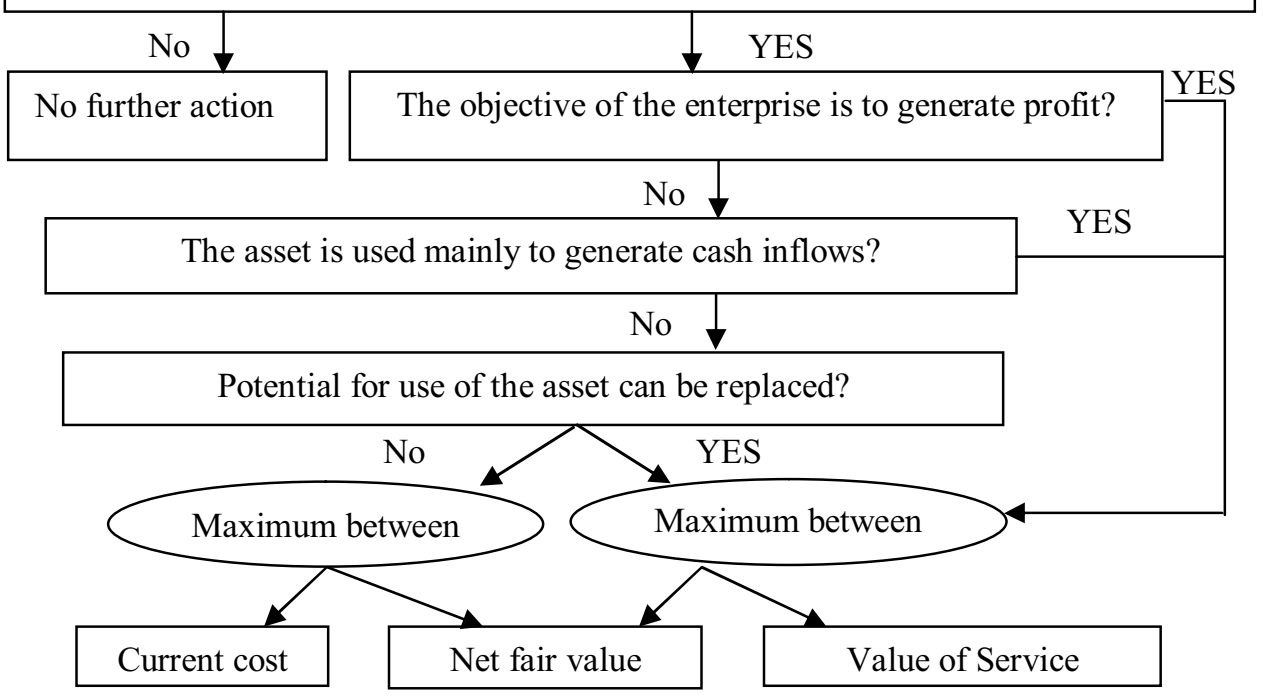

What is the situation in Romania? By OMFP no. 3.055/2009, the evaluation of assets is in line with norms. The valuation in the financial statements is made by respecting the precautionary principle taking into account all adjustments of value due to depreciation. On balance the Romanian companies will evaluate the fixed assets by comparing the book value to that determined based on inventory, the less differences between inventory value and net book value is highlighted in the accounts is an additional depreciation - if the impairment is irreversible, or is made an adjustment for depreciation or loss of value - where impairment is reversible. There is such an alignment of Romanian accounting regulations to the provisions of IFRS, recognition of assets at year following their recoverability principle, if we consider the value of inventory as a proponent of market value, and also following good utility for the enterprise.

With the promulgation of IAS 36 is ensure a consistent approach to reverse the loss of value, removing the specific practices such differences arising as a result of the different treatments. In the chain of procedures for determining the depreciation of an asset/cash generating unit is required first the crossing of identification phase possible impaired assets, is need a strict application of a professional reasoning to each business. Applying the impairment test is not random and not all assets of an enterprise. In general, the standard requires that companies to impairment tests when there are signs that an asset may be impaired (but annually for intangible assets with indefinite useful life and commercial fund). Standard requirement consider difficult and uncertain the capacity of intangible assets, especially those that are not yet available for use, for generate sufficient future economic benefits to ensure the recoverability of their accounting value, for this are impose annual impairment testing is required of them. For all other assets at each financial reporting date, the company must 
determine whether there are circumstances who indicate that depreciation could occur. Note that this is not a requirement that the possible depreciation is calculated for all assets at each balance sheet date, which would require a very demanding task for many businesses. It is, rather, the existence of conditions that might suggest an increased risk of impairment to be assessed. Thus, on balance it is necessary to identify those assets which, under the conditions considered, may be impaired. The existence conditions, the cues that impairment does not necessarily mean, however, the company should consider the recoverable amount of those assets. How the impairment test is complex process and quite expensive for some companies (difficulties related to the possibility of determining the market value of assets, and no projections of cash flows over the medium term reliable local economic conditions, also to determine the discount rate cash flow is necessary to make the assumptions and make some assumptions that are not always defensible) in measuring the recoverable amount will apply the principle of materiality. If in previous exercises the asset under review was established an recoverable value significantly higher than the net book value, and elapsed time indications that the asset has lost value does not consists of events that leads to reduce this difference, then it is not necessary an re-estimations recoverable amount.

Example 1:

An international transport company is operating with a whole fleet of buses that carry different routes without any of the buses to be dedicated to a route. Also, the company owns a truck used for transportation of goods, on request. The TIR can be subject to an individual analysis existing the possibility of determine the cash flows generated by its use, and an active market to establish market value of TIR's. The latest estimate of recoverable amount of TIR's been achieved in 2008 and it exceeded twice book value. The balance of 2009 there were indications that the asset might be impaired, as indicated an impairment but not so severe as to exceed the difference between the estimated recoverable amount and carrying amount of TIR 2008's, the company has not considered necessary the recoverable amount reestimations.

Also, if the asset review will still be used without being in the near future the company intends to dispose of (recoverable value based on value in use), even when the market recorded a change in interest rates which may reduce recoverable amount, the company will not re-estimated recoverable amount:

- if changes of the market interest rate do not affect the actualizations rate from which were determined using discounted future cash flows in estimating value in use;

- If there are opportunities to counteract the changes in the discount rate through increases in future cash flows due to, for example, improved market share.

The identification of impaired assets provides a standard set of indicators of potential impairment and suggests that they represent a minimum list of factors to be taken into account. The first analysis will take into account signals impairment criteria grouped into: external criteria and internal criteria. Criteria's or external cues are, primarily the result of a technological break at the enterprise, the lower level of activity, reduce product prices degradation future work prospects of the company, changes in the discount rate. Internal cues are generated by wear, performance degradation that the assets, adjustments in business activity (restructuring or closure), etc... It's all internal information leading to the idea that in future asset performance will be lower. Of the two categories of sources an important and particular attention needs the criteria's or external sources that are external to the enterprise cannot be influenced by it and management. The simple fact that one or more of the signals above suggests that there may be concerns about the possible impairment of an asset do not necessarily mean that he must undergo surgery for an impairment test. However, in the 
absence of plausible explanations as to why the signs of possible impairment should not be considered further, resulting that the presence of one or more of these inquiries would require monitoring. The company leaves the assessment signals a possible loss of value by observing the IAS 36 considers mandatory annual investigation, all indications of such depreciation "at each reporting date, the entities will check if there are indications of asset impairment. If such signs are identified, the entity shall estimate the recoverable amount of the asset". Possibility afforded by IAS 36 "Impairment of Assets" to choose in determining recoverable amount, the two values is not accidental. It is considered that the company can recover the value of its assets through use or market capitalization. However, the measurement of the two values is a complex, very expensive for many businesses, owns estimates based on management company with a strong subjective load, which is reflected on the certainty and reliability of data obtained. Applying the test for impairment of fixed assets, at the end of the reporting period, there are signs of a possible loss of value involved in measuring recoverable amount. The standards, a company has two obvious ways to recover the value of its assets: by turning on an active market or use (as a result of extensive debate - IAS 36 Basis for Conclusions, which concluded that the common market assumptions and own modeling company does not provide a full reality, which is why it is chose between the two aggregate maximum consistent with the likely behavior management).

In theory, and in most and in practice, a company that makes rational choices would sell an asset if the fair value less costs to sell of it would be more than the use value of the asset and continue to use the asset if the value use would exceed the amount of recovery by sale. Thus, the economic value of an asset is measured in the most coherent way in relation to the higher of these two values as the company will retain or dispose of assets in accordance with what appears to be the best and most efficient use of it.

The identification of an impairment loss for an asset and measure the recoverable amount should be based on an investment analysis of estimated future cash flows expected to arise from either actively or by using market capitalization as:

$>$ where, according to information available, the net receivables of sale exceed cash flows from continued use, deciding the asset sale;

$>$ If, while operating the exploitation treasury flows are lower than initial estimates but the immediate sale involves a low price or if the potential future costs by making the asset can be recovered, the firm will still choose to use the asset.

Business decision is based on investment results of the analysis above, without the need to establish both values. Recoverable amount is the maximum of fair value less costs to sell and value in use, de-advancement net book value by either of the two is sufficient to consider the asset as not impaired. Usually, is easier to determine the fair value less costs by sell than use value. In standard definition, fair value less costs by sell is the amount you can get from the sale of an asset in a transaction voluntarily conducted on objective between interested parties in informed choice, minus the cost of disposal. As measured by market, where supply meets the seller's request, estimating the fair value less costs of disposal are often performed with certainty for business.

The objective of the company is to identify, on the market, the fair value of fixed assets from which to deduct the costs of removal from service. The savings established by the existence of the specialized markets for assets will not meet significant difficulties, the fair value is relatively easy to estimate for the enterprise. However, though IFRS frequently used notions so as fair value concepts, active market, etc.., the reality of the Romanian economy shows that for most assets, no active markets where we can assess the aggregate. It is possible to determine the fair value less costs by sell even if the asset is not traded on an active market. 
In these circumstances the company will review the information available on possible transactions in the past, with similar assets, which are known the market selling prices, also if any offers made for similar assets and the prices are at levels approximately similar to can make an estimate of the net fair value.

Without intention to conclude, for many, the concept of fair value does not know only one reality: the market value. This is not, however, only one way to measure the fair value, and providing the most objective because it is based on information outside the company, which it cannot influence in any way. Use of assessment techniques is an alternative method of valuation, in the absence of established market price.

Two approaches can meet, namely:

- The first is a method of analogy that is to call the market value of an similar asset, showing the distinctive identical or at least similar to those of the asset under review;

- The second approach is its exploitation of an asset using modeling techniques.

The method for determining the value of a property through analogy or similarity is, theoretically valid but in practice this is difficult to realize, since the concept of similar characteristics is often difficult to establish and demonstrate. And yet, sometimes it is not possible to determine the fair value less costs of disposal "in the absence of a basis for credible estimating of amount you could get from selling assets in a transaction conducted between interested parties on objective and informed concerned'. Where the asset is not considered a market value or cannot make reliable estimates of the amount you might get an undertaking from the sale thereof, shall require the measurement of value in use.

If the measurement of fair value less costs of sell is, often, a certainty for business, it is established, usually, on market the value in use involves estimates and updates in most cases based on subjective values. Moreover, its size is specific to each company; through modeling has a much higher degree of subjectivity and is also more difficult to be validated. The use value involves the updating of treasury flows attached to future use of the asset by using an appropriate discount rate. Estimating of the future treasury flows involves a high degree of uncertainty is quite subjective and depends entirely on the management team that could be faced with lack of treasury flow projections over the medium term reliable local economic conditions.

Also, to determine the discount rate of treasury flow is necessary to make hypothesis and make some assumptions that are not always easy to sustain. Perhaps that is why the company is required in shaping its forecasts on future treasury flows to estimates based on reasonable assumptions - will avoid excessive growth rates of income, significant reductions in costs expected considering the recent experience is a guide correct for the near future. It also will insist on choosing the most appropriate discount rate, knowing the fact that the measure decisively influences its recoverable amount the asset under review. The standard requires that the measure recoverable amount to be made for each activity, the exception is the case when the asset does not generate treasury inflows largely independent of those generated by other assets or groups of assets. For such cases the recoverable amount is calculated on cashgenerating unit to which the asset belongs.

\section{Bibliography}

1. Epstein B., Abbas A, "IFRS 2008 Interpretation and application of International Accounting and Financial Reporting”, Ed BMT Publishing House, 2009 


\section{Studies and Scientific Researches - Economic Edition, no. 15, 2010}

2. M. Manea, "Measurement and evaluation concerning the impairment of fixed assets", University Book Publishing House, Bucharest 2007

3. M. Ristea, coordinator, "Accounting for depreciation and asset impairment", Tribune Publishing House, Bucharest, 2009

4. *** IAS 36 "Impairment of Assets", revised in 2003 